\title{
Recurrent staphylococcal infections and the duration of the carrier state
}

\author{
BY LEONARD ROODYN \\ General Practitioner, Woodberry Down Health Centre, Medical Officer in Charge, \\ Inoculation Clinic, Hospital for Tropical Diseases, N.W. 1
}

(Received 12 August 1959)

\section{INTRODUCTION}

Staphylococcal infections are one of the commonest bacterial infections encountered in the general population. Among young adult males, for example Logan (1954), of the Central Register Office, found that the frequency of boils in general practice was only exceeded by the common respiratory infections.

In the course of a previous investigation on staphylococcal infections (Roodyn, 1954), it was noted that a significant proportion of patients subsequently developed recurrences. The period of observation in this study was, however, relatively short and the object of the present paper is to present the results of investigation on recurrent staphylococcal infections which extended over a period of 7 years. As far as could be determined this is the first published report of a long-term study of recurrent staphylococcal infections in which phage typing was employed. According to Elek (1959) there is no information available on the maximum duration of the carrier state. It is hoped, in this study, to demonstrate by a comparison of the strains isolated from each successive infection in particular patients that staphylococci may persist in the body for very lengthy periods.

It is also proposed to describe a technique that has been adapted for the isolation of staphylococci from the deeper layers of the skin in cases where chronic skin carriage appeared to be an important factor in the recurrence.

\section{CLINICAL MATERIAL}

The original series referred to above consisted of eighty-one patients who first presented with a boil or stye during the period 1951-52 inclusive. Since then, twenty-three patients developed further infections. In fourteen of these only one early recurrence was observed, but in nine there were recurrent attacks of boils at intervals through the study period defined below. It is with the latter group of patients with recurrent furunculosis that the present investigation is mainly concerned.

The study period extended from January 1951 until January 1959. Seventyfour of the original patients remained under observation for the whole of this time, but in seven patients the follow-up was limited to a period of 1-4 years only.

The term recurrence is here defined as a further staphylococcal infection regardless of site, but of identical phage type to that isolated from the original lesion. 


\section{METHODS}

As previously described in the original investigation (Roodyn, 1954), swabs were taken from the lesion and one nostril of patients who first presented during the period 1951-52 and were examined bacteriologically. All staphylococci were tested for antibiotic sensitivity and were phage typed. A record was thus available of the sensitivity to antibiotics and the phage type of the bacterial strain responsible for the original infection. Each subsequent infection in succeeding years was similarly investigated.

In addition to the above routine procedures a special technique was devised by which it was possible to culture staphylococci from the deeper layers of the skin. This method was an adaptation of the procedure used for obtaining skin smears in cutaneous leprosy at the Hospital for Tropical Diseases, London. In this study, only non-nasal carriers were investigated by this special technique owing to the possibility that skin contamination arose from a nasal source (Hare \& Ridley, 1958).

After a routine skin swab was taken, a wide area was washed thoroughly with hot water and soap and then dried with a sterile towel. The skin was then swabbed with Cetrimide $1 \%$ and after this had dried, a smaller area was painted with strong iodine solution, B.P. Another skin swab was again taken as a check of this sterile procedure for the skin surface. An area of skin was then pinched up between the thumb and forefinger of a sterile gloved hand so that local blanching was observed. A superficial incision of about $\frac{1}{4}$ in. was then made with a sterile scalpel, care being taken to avoid bleeding as sterile cultures frequently ensued from blood-stained fluid. A small quantity of tissue fluid was then taken up on a sterile platinum loop and plated out directly on a nutrient agar plate which was examined after over-night incubation at $37^{\circ} \mathrm{C}$.

\section{RESULTS}

\section{Recurrence rate in furunculosis}

Fifty-nine of the original eighty-one patients developed no further staphylococcal lesions. In fourteen other cases, an early local recurrence was observed within a few weeks of the initial lesion and then no further attacks occurred. Thus in seventy-two $(89 \%)$ of eighty-one patients observed for 8 years or so, there was a prolonged remission after the initial attack of boils.

\section{Phage typing in recurrent furunculosis}

Table 1 records the results of phage typing in the nine cases of recurrent furunculosis in which infections occurred throughout the study period. It will be seen. that, in all cases, the phage type isolated from each successive staphylococcal infection was identical with that isolated initially, regardless of the interval between attacks. For example, in Case 1, a phage type 3B/3C/55 was isolated from the pus of boils in the years 1951, 1953 and 1958. Similarly, in Case 2, an untypable strain was responsible for infections in 1952, 1953 and 1957: in Case 3, a strain $3 \mathrm{~B} / 3 \mathrm{C} / 55$ in 1952,1953 , and 1956. 
Table 1. Nine cases of recurrent furunculosis demonstrating persistence of staphylococci for periods up to 7 years

\begin{tabular}{|c|c|c|c|}
\hline Case & Date & Lesion & Phage type \\
\hline \multirow[t]{6}{*}{1} & 29. ix. 51 & $\begin{array}{l}\text { Abscess of finger } \\
N / S\end{array}$ & $\begin{array}{l}3 \mathrm{~B} / 3 \mathrm{C} \\
3 \mathrm{~B} / 3 \mathrm{C}\end{array}$ \\
\hline & 19. iii. 53 & $\begin{array}{l}\text { Boil of R. axilla } \\
\text { N/S }\end{array}$ & $\begin{array}{l}3 \mathrm{~B} / 3 \mathrm{C} \\
3 \mathrm{~B} / 3 \mathrm{C}\end{array}$ \\
\hline & 21. iv. 53 & $\begin{array}{l}\text { Boil of R. axilla } \\
\text { N/S }\end{array}$ & $\begin{array}{l}3 \mathrm{~B} / 3 \mathrm{C} \\
3 \mathrm{~B} / 3 \mathrm{C}\end{array}$ \\
\hline & 23. xii. 53 & $\begin{array}{l}\text { Abscess of eyelid } \\
\text { N/S }\end{array}$ & $\begin{array}{l}3 \mathrm{~B} / 3 \mathrm{C} \\
3 \mathrm{~B} / 3 \mathrm{C}\end{array}$ \\
\hline & 17. iii. 58 & $\begin{array}{l}\text { Boil of face } \\
\text { N/S }\end{array}$ & $\begin{array}{l}3 \mathrm{~B} / 3 \mathrm{C} \\
3 \mathrm{~B} / 3 \mathrm{C}\end{array}$ \\
\hline & 7. ix. 58 & $\begin{array}{l}\text { Boil of neck } \\
\text { N/S }\end{array}$ & $\begin{array}{l}3 \mathrm{~B} / 3 \mathrm{C} \\
3 \mathrm{~B} / 3 \mathrm{C}\end{array}$ \\
\hline \multirow[t]{3}{*}{2} & 27. ii. 52 & $\begin{array}{l}\text { Boil of elbow } \\
\text { N/S }\end{array}$ & - \\
\hline & 12. iii. 53 & $\begin{array}{l}\text { Boil of face } \\
N / S\end{array}$ & $\begin{array}{l}- \\
-\end{array}$ \\
\hline & 4. iv. 57 & $\begin{array}{l}\text { Boil of face } \\
\text { N/S }\end{array}$ & $\begin{array}{l}- \\
-\end{array}$ \\
\hline \multirow[t]{3}{*}{3} & 1. x. 52 & $\begin{array}{l}\text { Boil of L. leg } \\
\text { N/S }\end{array}$ & $\begin{array}{l}3 \mathrm{C} / 3 \mathrm{~B} / 55 \\
3 \mathrm{C} / 3 \mathrm{~B} / 55\end{array}$ \\
\hline & 10. ii. 53 & $\begin{array}{l}\text { Boil of face } \\
\text { N/S }\end{array}$ & $\begin{array}{l}3 \mathrm{C} / 3 \mathrm{BB} / 55 \\
3 \mathrm{C} / 3 \mathrm{~B} / 55\end{array}$ \\
\hline & 10. x. 56 & $\begin{array}{l}\text { Boil of thigh } \\
N / S\end{array}$ & $\begin{array}{l}3 \mathrm{C} / 3 \mathrm{~B} / 55 \\
3 \mathrm{C} / 3 \mathrm{~B} / 55\end{array}$ \\
\hline \multirow[t]{2}{*}{4} & 30. vii. 53 & $\begin{array}{l}\text { Boil of axilla } \\
\text { N/S }\end{array}$ & $\begin{array}{l}52 \mathrm{~A} \\
\text { No staphylococci }\end{array}$ \\
\hline & 11. vii. 57 & $\begin{array}{l}\text { Boil of axilla } \\
\text { N/S }\end{array}$ & $\begin{array}{l}\text { 52A } \\
\text { No staphylocoeci }\end{array}$ \\
\hline \multirow[t]{3}{*}{$\mathbf{5}$} & 29. xii. 52 & $\begin{array}{l}\text { Boil of back of neck } \\
\text { N/S }\end{array}$ & $\begin{array}{l}- \\
-\end{array}$ \\
\hline & 27. iv. 53 & Boil of axilla & - \\
\hline & 20. xi. 57 & Boil of face & - \\
\hline \multirow[t]{2}{*}{6} & 1. x. 52 & $\begin{array}{l}\text { Boil of leg } \\
\text { N/S }\end{array}$ & No staphylococci \\
\hline & 9. xi. 57 & $\begin{array}{l}\text { Boil of leg } \\
\text { N/S }\end{array}$ & 77 very weak \\
\hline \multirow[t]{2}{*}{7} & 29. ix. 51 & $\begin{array}{l}\text { Boil of axilla } \\
\text { N/S }\end{array}$ & $\begin{array}{c}3 \mathrm{~B} / 3 \mathrm{C} \\
-\end{array}$ \\
\hline & 21. iv. 53 & $\begin{array}{l}\text { Boil of hand } \\
\text { N/S }\end{array}$ & $\begin{array}{l}3 \mathrm{~B} / 3 \mathrm{C} \\
3 \mathrm{~B} / 3 \mathrm{C}\end{array}$ \\
\hline \multirow[t]{2}{*}{8} & 17. ii. 55 & $\begin{array}{l}\text { Boil of axilla } \\
\text { N/S }\end{array}$ & $\begin{array}{l}47 / 53 / 54 \\
29\end{array}$ \\
\hline & 13. ii. 58 & $\begin{array}{l}\text { Boil of axilla } \\
\text { N/S }\end{array}$ & $\begin{array}{l}47 / 53 / 54 \\
29\end{array}$ \\
\hline \multirow[t]{3}{*}{9} & 6. v. 52 & $\begin{array}{l}\text { Boil of chin } \\
\text { N/S }\end{array}$ & $\begin{array}{l}52 \mathrm{~A} \\
52 \mathrm{~A}\end{array}$ \\
\hline & 24. ix. 52 & $\begin{array}{l}\text { Boil of leg } \\
\text { N/S }\end{array}$ & $\begin{array}{l}52 \mathrm{~A} \\
52 \mathrm{~A}\end{array}$ \\
\hline & 12. xi. 58 & $\begin{array}{l}\text { Wound of finger } \\
N / S\end{array}$ & $\begin{array}{l}52 \mathrm{~A} \\
52 \mathrm{~A}\end{array}$ \\
\hline
\end{tabular}

- indicates no phage lysis. $\mathrm{N} / \mathrm{S}=$ nasal swab. 
From the evidence provided in Table 1, it would seem reasonable to deduce that recurrent episodes of infection represented, not re-infection by exogenous strains in susceptible individuals, but auto-infection from persistent staphylococcal foci in the body.

This investigation also provided information on the period for which staphylococci persisted in the body. Thus in the nine cases described in Table 1, staphylococci were isolated from successive infections over the following lengths of time:

$\begin{array}{ll}\text { Over } 6 \text { years } & 2 \text { cases } \\ 4-5 \text { years } & 5 \text { cases } \\ 1 \frac{1}{2}-3 \text { years } & 2 \text { cases }\end{array}$

On consideration of Case 1 , for example, it is apparent that although the patient presented with a boil on 7 August 1958, she had in fact acquired the strain responsible for the lesion in 1951 or perhaps even earlier. The frequency distribution of the phage types of staphylococci recovered from recurrent cases therefore reflected the incidence of the different phage types at the time of infection.

Thus, in the twenty-three patients who had more than one episode of staphylococcal infection, the phage types of staphylococci isolated were as follows:

$\begin{array}{lr}\text { Group I } & 6 \\ \text { Group II } & 11 \\ \text { Group III } & 3 \\ \text { Resistant to lysis } & 3\end{array}$

As can be seen, there was a preponderance of infections due to Group II strains. All but four of these patients were infected during the years 1950-52 or perhaps even earlier. During those years, Group II strains were overall the most frequent cause of superficial staphylococcal lesions (Rountree, 1953; Roodyn, 1954). The high incidence of these strains in recurrent furunculosis reflected their frequency during 1950-52 when these patients were infected.

During 1951-53, Group II strains accounted for $43 \%$ of all the penicillin sensitive strains isolated from boils and styes (Rountree, 1953; Roodyn, 1954).

Although the small numbers obtainable from a single practice may not be suitable for statistical analysis it would appear that at the present time there may have been a reduction in the frequency of Group II strains in the general population. Thus of thirty-eight strains of staphylococci isolated from new cases of boils and styes during the years 1957-58, only eleven (29\%) belonged to Group II.

\section{Sources of staphylococci in recurrent furunculosis}

The sources are described under the following headings: (1) the skin, (2) the nose, (3) the perineum.

\section{The skin}

In view of the frequency of cutaneous staphylococcal lesions, it did not seem unreasonable to assume that chronic skin carriage was an important factor in recurrent infections. Many such patients, however, were also nasal carriers of a strain identical with that found in the original lesion and, even when persistent 
skin carriage was demonstrated, there was always the possibility that the cutaneous staphylococci were nasal in origin.

Two patients were encountered in whom staphylococci persisted in the skin for many months, and in both cases it was possible to exclude auto-infection from a nasal source. In the first patient, nasal swabs grew staphylococci of a different phage pattern from those isolated from the lesion and the skin. In the second case, no staphylococci were isolated after repeated examination of the nose. It was possible to show in these patients a persistent skin carriage (in the absence of nasal staphylococci) which continued for 3 years in the first patient and for 5 years in the second. Moreover, using the special technique described, it was shown that the deeper layers of the skin harboured staphylococci after they had disappeared from the surface.

Case 1. This patient, a male aged 30 years, first came under observation on 17 February 1955 and he did not form one of the original series of eighty-one patients. He was suffering from an extensive folliculitis of the right axilla which extended down the inner aspect of the right upper arm. There were approximately sixty pus-containing follicles to be seen, each the size of a pin's head.

Bacteriological investigation gave the following results:

(1) Pus from two widely separated follicles: Staph. aureus. Phage type 47/53/54.

(2) Nasal swab: Staph. aureus. Phage type 29.

(3) Two superficial skin swabs taken 3 in. and 6 in. from the outermost follicle of the axillary region: Staph. aureus. Phage type 47/53/54.

(4) Deep swabs taken after incision of the skin: Staph. aureus. Phage type $47 / 53 / 54$.

There was, therefore, a most extensive contamination of the whole axillary region with staphylococci of phage type 47/53/54. Moreover, this involved both the deeper and superficial layers of the skin. Auto-infection from a nasal source played no part.

He was treated with $3 \%$ chlortetracycline ointment and, after 7-10 days, the folliculitis completely subsided. Nevertheless, he remained a persistent skin carrier, as superficial swabs taken from the axillary region on 18 March 1955 and on 3 April 1955 yielded a heavy growth of Staph. aureus although the axilla looked normal.

The patient remained free from further infections for 3 years until 13 February 1958, when he again developed a folliculitis of the right axilla. Bacteriological results were:

(1) Pus from a follicle: Staph. aureus. Phage type 47/53/54.

(2) Nasal swab: Staph. aureus. Phage type 29.

(3) Superficial and deep skin swabs: Staph. aureus. Phage type 47/53/54.

Case 2. This patient, a woman aged 39 years, presented on 1 October 1952 with an extensive folliculitis of the front of both legs. The following results were obtained at that time:

Nasal swab: No staphylococci isolated.

Pus from a lesion: Staph. aureus present. Resistant to penicillin. Resistant to phage lysis. 
Surface skin swabs were taken from normal-looking skin 3 in. and 6 in. from a pustule: Staph. aureus. Resistant to penicillin. Resistant to phage lysis.

It must be enphasized that strains resistant to phage lysis constituted only $12 \%$ of all strains isolated from the pus of boils (Roodyn, 1954), so that there was a probability that the staphylococci isolated from the healthy looking skin around the pustules were identical with those responsible for the lesion.

She was treated with Cetrimide $1 \%$ and boracic acid dusting powder. Several further attacks of folliculitis occurred, but after about 3 weeks the lesions dis. appeared and the legs appeared normal.

On 9 November 1957, some 5 years after the original outbreak, she again developed an extensive folliculitis of the left leg.

Investigation showed:

(1) Nasal swab: no staphylococci.

(2) Pus from a lesion: Staph. aureus present. Resistant to penicillin. Resistant to phage lysis.

(3) Surface skin swab: Staph. aureus present. Resistant to penicillin. Resistant to phage lysis.

On this occasion, she was treated with $3 \%$ chlortetracycline ointment and the condition healed within 2 weeks. Further skin tests were, however, continued to determine for how long staphylococci could be recovered from the healthy looking skin around the lesion.

12 February 1958. Superficial skin swabs from the front of the left leg: Staph. aureus present. Resistant to penicillin. Resistant to phage lysis.

3 March 1958. Superficial skin swab: Staph. aureus present. Resistant to penicillin. Resistant to phage lysis.

10 April 1958. When the leg looked quite normal the following results were obtained:

Superficial skin swab: no staphylococci present.

Swab taken after incision of skin: moderate growth of Staph. aureus. Resistant to penicillin. Resistant to phage lysis.

From the investigations carried out in this case, it would appear probable that there was a persistent skin carriage of staphylococci in the skin of the legs for several months. Moreover, from the fact that the staphylococci recovered after an interval of 5 years resembled in their reaction to phages and to penicillin those isolated originally, it is possible that staphylococci may have persisted in the skin for as long as 5 years.

\section{The nose}

The nasal carriage state of all the twenty-three patients who suffered from one or more recurrences was as follows:

Identical strain in the nose and lesion

Different strain in the nose and lesion

No nasal staphylococci

There was, therefore, a high nasal carriage state in recurrent furunculosis. 
Moreover, as Table 1 indicates, the staphylococci in the anterior nares showed great persistence. Thus in Case 1 , staphylococci of phage type $3 \mathrm{~B} / 3 \mathrm{C} / 55$ were isolated on six occasions over a period of 7 years.

The duration of the nasal carrier state in the five cases recorded in Table 1 in which identical strains were present in the nose and lesion were as follows:

\section{Case 1 at least 7 years \\ Case 2 at least 5 years \\ Case 3 at least 4 years \\ Case 5 at least 5 years \\ Case 9 at least 6 years}

\section{The perineum}

In the following case of an infant who was born in a maternity hospital, the presence of staphylococci in the perineal region appeared to be responsible for recurrent lesions.

Case 5. On 11 May 1957 this infant, of 4 weeks of age, had four small boils of the right buttock. The following bacteriological results were obtained:

Pus from boil: Staph. aureus present. Phage 52/80. Resistant to penicillin.

Nasal swab: Staph. aureus present. Phage 52/80. Resistant to penicillin.

Swab from perineum: Staph. aureus present. Phage 52/80. Resistant to penicillin.

\section{DISCUSSION}

From the prolonged study of eighty-one patients with staphylococcal lesions, it was apparent that in the majority of cases infection was limited to a relatively short period which was followed by freedom from further attacks. Nine (11\%) of the eighty-one patients, however, suffered from recurrent attacks of boils in which the same phage type of staphylococcus was recovered from the pus on successive occasions for nearly 7 years in some of the cases.

From the fact that a particular strain reappeared time and time again, it can be inferred that staphylococci persisted in the body for long periods even in the absence of frank pus. Repeated new infections in susceptible individuals would probably have been associated with the appearance of different phage types of staphylococci at each episode of infection. This finding has some importance in all studies of the frequency distribution of the different phage types and the incidence of drug-resistant strains. It is essential to distinguish between new infections and a recurrence of infection in which the strain responsible for the infection may have been acquired many years previously.

Nasal carriage of staphylococci may also persist for many years, although in some cases this may be intermittent (Gould \& McKillop, 1954). In the present study, in two of the five patients who carried an identical strain in the nose and lesion, the same strain was isolated on successive occasions from the anterior nares for a period of over 6 years.

Chronic skin carriage has been found to occur in the absence of nasal colonization. Frequent, repeated swabbing revealed that staphylococei persisted in the skin around a lesion for many months and probably for as long as 3-5 years. It 
is in such cases that the special skin technique proved particularly useful as it indicated that skin carriage in the deeper layers persisted for a longer period than surface carriage. This confirmed the work of Gillespie, Devenish \& Cowan (1939) who found that staphylococci could still be obtained from the perspiration inside gloves after sterilization of the skin surface.

This concept of a prolonged persistence of an organism in the skin for many years, even in the absence of obvious lesions, is not unknown in other bacterial, viral and even protozoal infections of the skin. For example, in herpes simplex the virus tends to persist for many years; in leprosy Mycobacterium leprae can persist in the skin for 20 years or so with long periods of remission and even a protozoan such as Leishmania tropica may be present in the skin for many months before an Oriental Sore becomes manifest (Woodruff, 1959). In cases of recurrent osteomyelitis, the prolonged persistence of staphylococci in bone tissue is well known and Blair (personal communication, 1958) has found that at each recurrence, the original phage type of staphylococcus reappeared, as in the cases of recurrent boils in this study, regardless of the interval between infections.

In recurrent furunculosis one presumes there is an unstable host-parasite relationship in which the staphylococci, although present in the body for long periods, remain in check by the body defences. When these are disturbed, resistance to these organisms was lowered and overt disease developed.

Many general factors affecting resistances are known-for example, vitamin deficiency (Turner, 1929), endocrine factors (Chase, White \& Dougherty, 1946), starvation (Smith \& Dubos, 1956) and diabetes mellitus (Greenwood \& Rockwood, 1930); all can alter susceptibility to staphylococcal infection. Clinically, however, it has been almost impossible to determine in a case of recurrent furunculosis the factor responsible for the disturbance of the host-parasite relationship.

In this study, staphylococci of phage pattern $3 \mathrm{~B} / 3 \mathrm{C} / 55$ were responsible for most of the recurrent infections. It is not suggested, however, that this represents heightened powers of persistence in staphylococci of this type. At the time when these patients acquired the staphylococci the strains were particularly common in the general population. New cases of staphylococcal infection occurring at the present time appear to be caused more frequently by organisms belonging to Group I strains.

\section{SUMMARY}

An investigation has been carried out over a period of 7 years of a series of eighty-one patients who first presented in 1951-52 with staphylococcal lesions. In seventy-two cases $(89 \%)$ ) the infection was limited to a single, short episode of infection without recurrence. But nine patients $(11 \%)$ developed recurrent lesions throughout the period. In these patients, from a comparison of the phage types isolated from successive infections, it was inferred that the organism had persisted in the body for over 6 years in two cases, for 4-5 years in five cases and for 1.3 years in three cases.

Nasal carriage also persisted for over 6 years in two cases and for 3-5 years in three cases. 
In two cases, chronic skin carriage occurred in the absence of nasal carriage. There was persistence of staphylococci for 3 and 5 years in these cases, and the use of a special technique revealed that carriage in the deeper layers of the skin was particularly important.

The frequency distribution of phage patterns isolated in recurrent cases reflected the high incidence of Group II strains at the time when the strains were first acquired. New infections which arose in 1957-58 no longer showed this preponderance of Group II strains, as only eleven ( $28 \%$ ) of thirty-eight new infections were caused by this group.

The bacteriological examinations were mostly carried out by the Central Public Health Laboratory, Colindale, and I wish to express my gratitude to Dr R. E. O. Williams of the Staphylococcal Reference Laboratory, for his assistance in this work. I am also grateful for the laboratory facilities afforded me by Dr Ridley at the Hospital for Tropical Diseases for the performance of the skin carriage testing.

\section{REFERENCES}

Chase, J. H., White, A. \& Dovgherty, T. F. (1946). J. Immunol. 52, 101. Livingstone. EuEK, S. D. (1959) Staphylococcus pyogenes and its relation to disease, p. 155. Edinburgh:

Livingstone.

Gillespie, E. H., Devenish, E. A. \& Cowan, S. T. (1939). Lancet, ii, 870.

GouLD, J. C. \& McKilLop, E. J. (1954). J. Hyg., Camb., 52, 304.

Greienwood, A. M. \& Rockwood, E. M. (1930). Arch. Derm. Syph., N.Y., 21, 96.

HARe, R. \& RIDLEY, M. (1958). Brit. med. J. i, 69.

Logan, W. P. (1954). Practitioner, 173, 188.

ROODYN, L. (1954). Brit. med. J. ii, 1322.

ROONTREe, P. M. (1953). Lancet, i, 514.

Sмтт, J. M. \& Dubos, R. J. (1956). J. exp. Med. 193, 109.

TURner, R. G. (1929). J. Infect. Dis. 45, 208.

WoODRUFt, A. W. (1959). Trans. R. Soc. trop. Med. Hyg. 53, 36. 